\title{
Avaliação da Resistência de Aderência à Tração de Revestimento Cerâmico em Substrato de Gesso
}

\author{
Evaluation of the adhesion strength to traction of ceramic coating on substrate of plaster
}

\author{
Emmanuel Inácio ${ }^{1}$ (iD orcid.org/0000-0003-4972-5363 \\ Bárbara Costa ${ }^{2}$ (id) orcid.org/0000-0001-9619-2032 \\ Ângelo Just ${ }^{2}$ (id) orcid.org/0000-0002-0759-6439 \\ Luciano Peres 3 (iD) orcid.org/0000-0001-7923-3234 \\ ${ }^{1}$ Departamento de Engenharia Civil, Universidade Maurício de Nassau, Recife, Brasil, \\ 2 Departamento de Engenharia Civil, Universidade de Pernambuco, Recife, Brasil, \\ 3 Pesquisador, Instituto de Tecnologia de Pernambuco, Recife, Brasil. \\ E-mail do autor principal: Emmanuel Inácio emmanuel.is@hotmail.com
}

\section{Resumo}

O objetivo desse trabalho é avaliar a resistência de aderência à tração do revestimento cerâmico aplicado com diferentes argamassas e gesso-cola em substrato de pasta de gesso, a fim de ressaltar a importância de ações preventivas para evitar manifestações patológicas decorrentes de falhas construtivas ou falta de conhecimento do sistema adotado. O estudo de caso foi realizado em uma edificação residencial de 13 pavimentos situada na Região Metropolitana do Recife. Para cada tipo de argamassa foram ensaiados 12 corpos de prova, o mesmo procedimento foi adotado para o gesso-cola. Na normatização brasileira não existem parâmetros para o sistema adotado, portanto foram utilizados limites determinados para o revestimento de argamassa. Entre os resultados obtidos, apenas o gesso-cola standard atendeu ao requisito normativo. Porém, através da análise da forma ruptura, pode-se verificar que as camadas de gesso e a interface substrato-gesso apresentaram os valores mais altos e mais baixos. Dessa forma, acarretando a falha de aderência à execução do revestimento de gesso e não ao tipo de assentamento. Esse trabalho contribui para o meio acadêmico e técnico colocando em discussão a utilização do gesso em áreas molhadas e molháveis, abrindo precedentes para um estudo mais amplo sobre este tema.

Palavras-Chave: Aderência; Gesso; Revestimento; Argamassa.

\begin{abstract}
The objective of this work is to evaluate the adhesion strength to the traction of the ceramic coating applied with different mortars and gypsum glue on gypsum paste substrate, in order to emphasize the importance of preventive actions to avoid pathological manifestations due to constructive failures or lack of Knowledge of the adopted system. The case study was carried out in a residential building of 13 floors located in the Metropolitan Region of Recife. For each mortar type, 12 specimens were 149

http: / / dx.doi.org/10.25286/repa.v2i3.709
\end{abstract}


tested, the same procedure was adopted for gypsum. In the Brazilian standardization there are no parameters for the system adopted, therefore, certain limits were used for the mortar coating. Among the results obtained, only the standard plasterboard met the normative requirement. However, through the analysis of the rupture form, it can be verified that the gypsum layers and the substrate-gypsum interface presented the highest and lowest values. In this way, causing the adhesion failure to the execution of the plaster coating and not to the type of laying. This work contributes to the academic and technical environment by discussing the use of gypsum in wet and wet areas, setting the precedents for a broader study on this subject.

Key-words: Adhesion; Plaster; Coating; Mortar.

\section{Introdução}

As argamassas de revestimento são utilizadas para revestir paredes, muros e tetos, e posteriormente, receberem acabamento cerâmico ou pintura. O revestimento deve auxiliar no isolamento acústico e térmico, apresentar boa estanqueidade à água, segurança ao fogo e resistência ao desgaste e abalos superficiais [1].

Outra característica relevante do revestimento é a aderência ao substrato, produto da ancoragem mecânica da argamassa nas reentrâncias e saliências microscópicas da base, que comumente apresenta manifestações patológicas de descolamento. A aderência depende da forma de aplicação, das características da base, do tipo de argamassa utilizada e do sistema escolhido para a execução do revestimento [2]. A aderência não é uma propriedade da argamassa e sim da interação das camadas do sistema que se pretende avaliar [3].

De acordo com o trabalho de Costa e Jhon [4], o processo de aderência ocorre em toda a superfície entre o substrato e a matriz cimentícia e tem início ainda na fase plástica do material, evoluindo ao longo do tempo devido à cinética de hidratação e absorção da base. Ligações químicas e ações mecânicas em toda interface mantém a aderência do revestimento.

As propriedades da argamassa escolhida para o revestimento e o método de aplicação devem fornecer ao sistema condições favoráveis de acordo com o acabamento estabelecido em projeto, bem como os critérios de aceitação devem ser definidos, a fim de mitigar falhas que afetem a qualidade final do produto [5].

O objetivo desse trabalho é apresentar a importância dos ensaios de resistência de aderência à tração para evitar possíveis manifestações patológicas, avaliando essa propriedade no estudo de caso de revestimento cerâmico em substrato de gesso, com diferentes argamassas de assentamento e gesso-cola.

\section{Procedimento Executivo de Revestimento de Paredes Internas}

\subsection{Revestimento de Gesso}

O gesso, originado a partir da calcinação da gipsita, quando utilizado na construção civil, é classificado como fino ou grosso e de revestimento ou fundição. Suas características devem atender as exigências químicas, físicas e mecânicas dispostas na ABNT NBR 13207 [6].

A produção brasileira de gesso é estimada em duas toneladas, tendo o Nordeste do país como o maior fabricante desse material. Um montante de aproximadamente $90 \%$ do gesso do país é produzido no Polo Gesseiro do Araripe, localizado a $680 \mathrm{~km}$ do litoral pernambucano [7].

Para ser entregue na obra, o gesso deve ser embalado e armazenado corretamente a fim de manter as características do material: o saco precisa apresentar várias camadas de papelão e sua massa liquida não ultrapassar $40 \mathrm{~kg}$, para evitar rupturas e facilitar o manuseio. Empilhados, os sacos sobrepostos devem ter no máximo 20 unidades em cima de paletes, sem contato com o piso [6].

A pasta de gesso empregada no revestimento interno deve apresentar aderência e endurecimento compatíveis com a função ao qual está sendo destinada, podendo ser acrescido à mistura aditivos em pequenas proporções, mas que não sejam nocivos ao acabamento que a base receberá. O revestimento de gesso, quando aplicado em áreas que apresentem percolação de água, deve haver um planejamento para o tratamento com material impermeabilizante na superfície [8]. 
O revestimento de gesso pode ser desempenado ou sarrafeado. Em ambas as metodologias, apresenta indicadores elevados de produtividade e economia de material. O melhor desempenho é garantido a depender da forma de calcinação da gipsita, módulo de finura, água de amassamento e a presença de impurezas ou aditivos na composição. A base em que o gesso será aplicado, bloco de concreto ou outro material cimentício, deve estar executada há mais de um mês, em função da alta taxa de absorção de água. É recomendável que a espessura do revestimento não ultrapasse $5 \mathrm{~mm}$, devido à possibilidade do surgimento de fissuras provenientes às movimentações da estrutura que geram deformações na alvenaria [9].

\subsection{Revestimento Cerâmico}

A ABNT NBR 14081 [10], que estabelece diretrizes para a argamassa colante para assentamento de placas cerâmicas, é dividida em 5 partes: requisitos, execução do substrato padrão e aplicação da argamassa para ensaios, determinação do tempo em aberto, determinação da resistência de aderência à tração, e determinação do deslizamento. Vale ressaltar que os ensaios dispostos nos anexos dessa norma são para condições laboratoriais.

Quanto à aderência do revestimento cerâmico, objeto desse trabalho, a argamassa colante deve atender aos requisitos dispostos na Tabela 1 .

Tabela 1: Propriedades fundamentais para argamassas colantes.

\begin{tabular}{|c|c|c|c|c|c|c|}
\hline \multicolumn{2}{|c|}{ Requisito } & $\begin{array}{c}\text { Método } \\
\text { de }\end{array}$ & Und & ACI & $\begin{array}{c}\text { ACI } \\
\text { I }\end{array}$ & $\begin{array}{c}\text { ACI } \\
\text { II }\end{array}$ \\
\hline \multirow{3}{*}{$\begin{array}{l}\text { Resistênci } \\
\text { a de } \\
\text { aderência } \\
\text { à tração } \\
\text { aos } 28 \\
\text { dias, em } \\
\text { função do } \\
\text { tipo de } \\
\text { cura }\end{array}$} & $\begin{array}{l}\text { Cura } \\
\text { normal }\end{array}$ & \multirow{3}{*}{$\begin{array}{c}\text { ABNT } \\
\text { NBR } \\
14081-4\end{array}$} & \multirow{3}{*}{$\mathrm{MPa}$} & $\begin{array}{c}\geq \\
0,5\end{array}$ & $\begin{array}{c}\geq \\
0,5\end{array}$ & $\begin{array}{c}\geq \\
1,0\end{array}$ \\
\hline & $\begin{array}{c}\text { Cura } \\
\text { subme } \\
\text { rsa }\end{array}$ & & & $\begin{array}{c}\geq \\
0,5\end{array}$ & $\begin{array}{c}\geq \\
0,5\end{array}$ & $\begin{array}{c}\geq \\
1,0\end{array}$ \\
\hline & $\begin{array}{l}\text { Cura } \\
\text { em } \\
\text { estufa }\end{array}$ & & & & $\begin{array}{c}\geq \\
0,5\end{array}$ & $\begin{array}{c}\geq \\
1,0\end{array}$ \\
\hline
\end{tabular}

Por definição, argamassa colante é uma mistura de aglomerantes hidráulicos, agregados minerais e aditivos, que ao adicionar água forma uma pasta viscosa, plástica e aderente. Muita atenção deve ser dada a água de amassamento, que deve ser isenta de substâncias estranhas que possam ser prejudiciais ao desempenho do sistema [11].

Fiorito [12] cita os cuidados com o traço das argamassas, mas ressalta outras causas de manifestações patológicas em revestimentos, a saber: falta de previsão de juntas de assentamento e de movimentação, espessuras elevadas do revestimento sem as devidas ações preventivas, e a expansão por umidade das peças cerâmicas.

Bauer [13] reforça que as principais problemáticas nos revestimentos cerâmicos estão ligadas ao descolamento, seja por empolamento ou pulverulência. Ainda assim, a anomalia pode ser atribuída principalmente a aderência das camadas do revestimento à base, dito isso, a preparação com limpeza e chapisco, e atenção com a mistura dos componentes, é a ação preventiva mais eficaz.

\section{Metodologia}

O estudo de caso foi realizado em uma edificação residencial de 13 pavimentos situada na Região Metropolitana do Recife (RMR), composta por 48 unidades de $120 \mathrm{~m}^{2}$ cada. A alvenaria de periferia e as paredes que dividem as unidades foram executadas em bloco de concreto de $14 \mathrm{~cm}$ de espessura e as divisórias dos ambientes em bloco de gesso de $7 \mathrm{~cm}$. Nas áreas molhadas, as alvenarias de bloco de concreto foram revestidas com argamassa cimentícia e nas áreas molháveis, a exemplo da cozinha e área de serviço, foi utilizada pasta de gesso, que receberão posteriormente o revestimento cerâmico.

O estudo de resistência de aderência à tração foi realizado a fim de reduzir as chances de problemáticas decorrentes das ações químicas e físicas nas interfaces do sistema construtivo pasta de gesso e cerâmica.

Os testes foram executados com dois tipos de argamassa colante, ACII e ACIII, e com o gesso-cola standard e hidrofugante, totalizando 4 ensaios, orientados pela NBR 13749 [5]. Esta norma determina a execução de ensaios de resistência de aderência à tração, quando a fiscalização julgar necessário, a cada $100 \mathrm{~m}^{2}$ ou menos da área suspeita, em 12 pontos escolhidos aleatoriamente. 0 revestimento da área estudada será aceito se, dos 12 ensaios realizados (com idade igual ou superior a 28 dias), pelos menos 8 valores forem iguais ou superiores a 0,3MPa.

$$
\text { http: / / dx.doi.org/10.25286/repa.v2i3.709 }
$$


A aplicação da cerâmica com utilização da argamassa colante ACII foi realizada no dia 03/02/2017 e teve seu ensaio de resistência de aderência executado em 06/03/2017. Os demais ensaios tiveram seu revestimento assentado no dia 15/02/2017 e verificação da aderência 28 dias depois.

Durante a aplicação do revestimento, nos 4 ensaios realizados, foram tomados alguns cuidados para reduzir possíveis adulterações nos reais valores de resistência de aderência à tração, a saber: limpeza do substrato; preparação das argamassas colantes e do gesso-cola conforme informado pelos fornecedores, inclusive no atendimento ao traço; aplicação das argamassas colantes e gesso-cola com utilização de ferramentas adequadas (desempenadeira de aço denteada); e conformidade na extensão, quantidade e espessura da faixa de espalhamento.

Para a realização do ensaio de aderência, também foram adotadas precauções estabelecidas na NBR 13528 [3], a fim de se medir resultados confiáveis para os sistemas estudados, a exemplo da distribuição dos corpos de prova, corte do revestimento, limpeza da superfície, colagem das pastilhas metálicas e atendimento do tempo de cura estabelecido pelo fornecedor antes do início do teste de arrancamento.

As Figuras 1, 2, 3 e 4 ilustram a preparação e a realização do ensaio de resistência à tração para a argamassa colante ACII, ACIII, gesso-cola standard e gesso-cola hidrofugante, respectivamente.

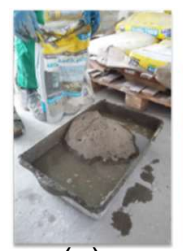

(a)
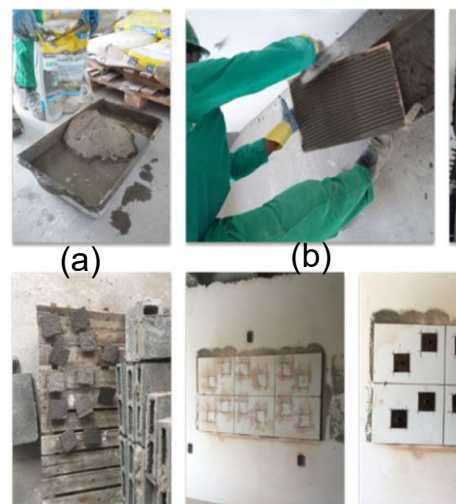

(e) (b)

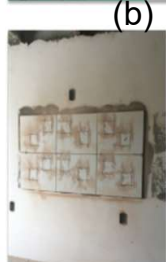

(f)

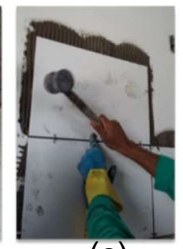

(c)

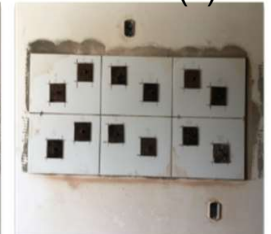

(g)

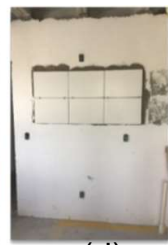

(d)

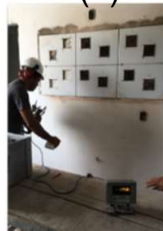

(h)
Figura 1: Ensaio com argamassa colante ACII.

(a) Preparação da ACII; (b) Espalhamento da argamassa em toda o tardoz da cerâmica; (c) Assentamento do revestimento cerâmico; (d) Revestimento assentado para realização do ensaio de aderência; (e) Aplicação da cola epóxi nas pastilhas metálicas; (f) Corte das 12 amostras do revestimento; (g) Colagem das pastilhas metálicas; (h) Ensaio de resistência de aderência à tração.

Fonte: Autores 2017

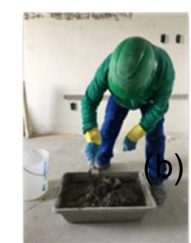

(a)

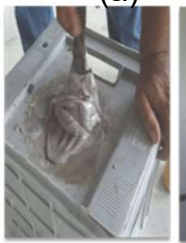

(e)

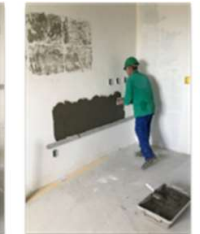

(b)

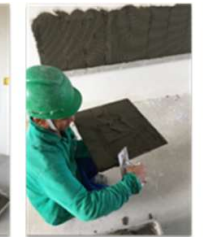

(c)

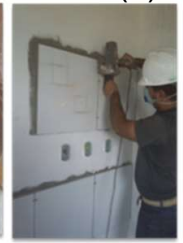

(f)

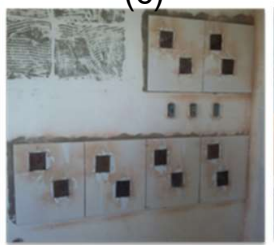

(g)

(h)

Figura 2: Ensaio com argamassa colante ACIII.

(a) Preparação da ACIII; (b) e (c) Espalhamento da argamassa no substrato de gesso e em toda o tardoz da cerâmica; (d) Assentamento do revestimento cerâmico; (e) Preparação da cola epóxi; (f) Corte das 12 amostras do revestimento; $(\mathrm{g})$ Colagem das pastilhas metálicas; $(\mathrm{h})$ Ensaio de resistência de aderência à tração.

Fonte: Autores (2017)

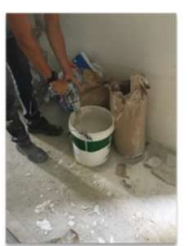

(a)

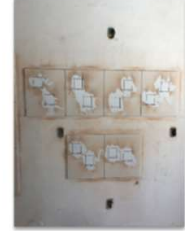

(e)

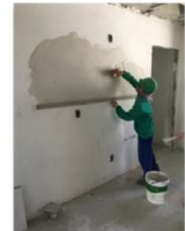

(b)

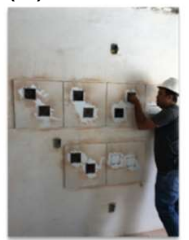

(f)

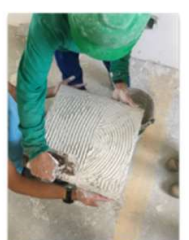

(c)

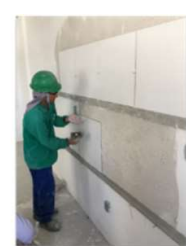

(d)

Figura 3: Ensaio com gesso-cola standard.

(a) Preparação do gesso-cola standard; (b) e (c) Espalhamento do gesso-cola no substrato de gesso e em toda o tardoz da cerâmica; (d) Assentamento do revestimento cerâmico; (e) Corte das 12 amostras do revestimento; ( $\mathrm{f}$ ) Colagem das pastilhas metálicas; $(\mathrm{g}$ ) Revestimento cerâmico após o ensaio de resistência de aderência à tração.

Fonte: Autores (2017) 


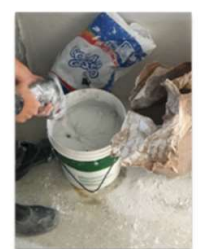

(a)

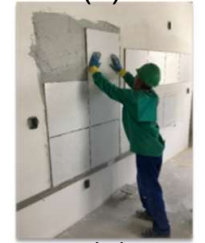

(e)

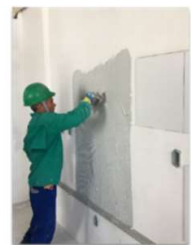

(b)

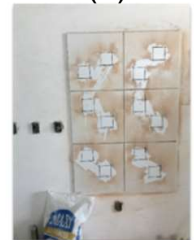

(f)

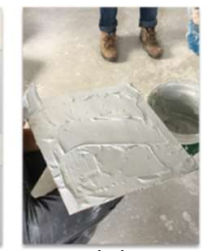

(c)

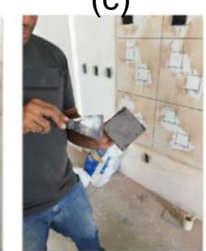

(g)

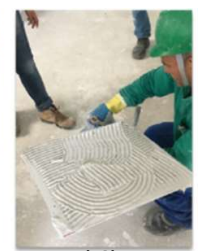

(d)

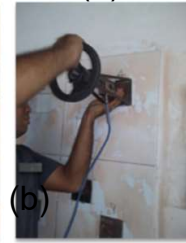

(h)
Figura 4: Ensaio com gesso-cola hidrofugante.

(a) Preparação do gesso-cola hidrofugante; (b) e (c) Espalhamento do gesso-cola no substrato de gesso e em toda o tardoz da cerâmica; (d) Criação de cordões no gesso-cola com utilização da desempenadeira de aço; (e) Assentamento do revestimento cerâmico; (f) Corte das 12 amostras do revestimento; ( $\mathrm{g}$ ) Aplicação da cola epóxi nas pastilhas metálicas; (h) Ensaio de resistência de aderência à tração.

Fonte: Autores (2017)

\section{Resultados e Discussões}

Para análise dos resultados dos ensaios realizados, adotou-se como referência os limites de resistência preconizados pela NBR 13749 [5], conforme Tabela 2.

Tabela 2: Limites de resistência de aderência à tração (Ra) para emboço e camada única.

\begin{tabular}{c|l|l|c}
\hline \multicolumn{2}{c|}{ LOCAL } & \multicolumn{1}{c|}{ ACABAMENTO } & \multicolumn{1}{c}{$\begin{array}{c}\text { Ra } \\
(\mathbf{M P a})\end{array}$} \\
\hline \multirow{2}{*}{ PAREDE } & \multirow{2}{*}{ INT. } & PINTURA OU BASE PARA REBOCO & $\geq 0,20$ \\
\cline { 3 - 4 } & \multirow{2}{*}{ EXT. } & CERÂMICA OU LAMINADO & $\geq 0,30$ \\
\cline { 2 - 4 } & PINTURA OU BASE PARA REBOCO & $\geq 0,30$ \\
\cline { 2 - 4 } & CERÂMICA & $\geq 0,30$ \\
\hline \multicolumn{2}{c|}{ TETO } & - & $\geq 0,20$ \\
\hline \multirow{2}{*}{$\begin{array}{c}\text { PISO } \\
\text { (INT./EXT.) }\end{array}$} & CERÂMICA & $\geq 0,30$
\end{tabular}

Fonte: adaptação da ABNT NBR 13749 [5].

De acordo com a Tabela 2, para acabamento do tipo cerâmico aplicado em parede, tema de estudo deste trabalho, o valor mínimo da resistência de aderência à tração considerado satisfatório para o bom desempenho deste sistema tem que ser igual ou maior do que 0,3MPa.

É importante salientar que os limites de referência para a resistência de aderência à tração apresentados acima são aplicáveis para argamassas cimentícias (emboço e/ou camada única), e só foram considerados pela inexistência de normas técnicas brasileiras que determinem o desempenho do revestimento cerâmico sobre a pasta de gesso.

\subsection{Resultados Para Argamassa Colante ACII}

No Gráfico 1 são apresentados os resultados para o ensaio de resistência de aderência à tração de cerâmica em substrato de gesso com utilização de argamassa colante ACII.

Gráfico 1: Resultados do ensaio com argamassa colante ACII

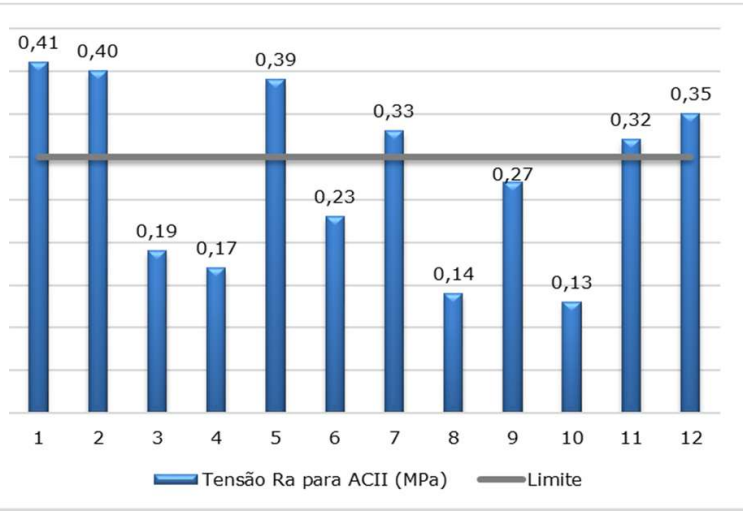

Fonte: Autores 2017

$\mathrm{Na}$ análise da forma de ruptura, constatou-se que os corpos de prova (CP's) 1, 2, 5, 7, 11 e 12, com Ra $\geq 0,3 \mathrm{MPa}$, tiveram grande parte de seus descolamentos concentrados entre o substrato (bloco de concreto) e a pasta de gesso, ou entre as camadas de gesso. Já os resultados abaixo do limite adotado, CP's 3, 4, 6, 8, 9 e 10, apontaram rupturas nas seguintes interfaces do sistema: entre as camadas de gesso, entre o substrato e o gesso, e entre a cerâmica e a argamassa colante. $\mathrm{O}$ resultado mais satisfatório, $0,41 \mathrm{MPa}$, rompeu $70 \%$ na interface substrato-gesso e $30 \%$ entre as camadas de gesso, enquanto o resultado mais baixo, $0,13 \mathrm{MPa}$, se rompeu $25 \%$ no substrato, $20 \%$ no substrato-gesso e $55 \%$ entre as camadas de gesso. É importante citar que a ruptura do CP 8 foi $100 \%$ localizada entre a cerâmica e a cola adesiva utilizada no ensaio. A baixa tensão encontrada http: / / dx.doi.org/10.25286/repa.v2i3.709 
para esta amostra pode ter sido causada por falha durante a colagem da placa metálica na cerâmica.

\subsection{Resultados Para Argamassa Colante ACIII}

Os resultados dos ensaios para a argamassa colante ACIII são apresentados no Gráfico 2.

Gráfico 2: Resultados do ensaio com argamassa colante ACIII

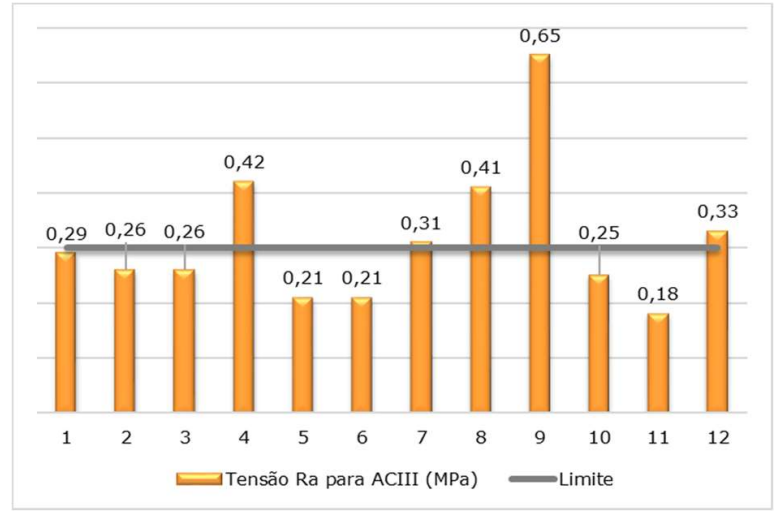

Fonte: Autores 2017

A análise da forma de ruptura revelou que os corpos de prova com resistência de aderência acima de 0,3MPa, $\mathrm{CP}^{\prime} \mathrm{s} 4,7,8,9$ e 12, romperam com maior frequência entre a interface substrato-gesso e entre as camadas de gesso, apresentando também descolamentos entre as camadas de substrato e as camadas de argamassa colante. Os CP's que apresentaram resistência de aderência menor que 0,3MPa, CP's 1, 2, 3, 5, 6, 10 e 11, registraram rupturas nas interfaces a seguir: camadas de gesso, substrato-gesso, camadas de argamassa colante e entre camadas do substrato. A maior tensão medida, $0,65 \mathrm{MPa}$, rompeu $55 \%$ entre as camadas de gesso, $35 \%$ na interface substrato-gesso e $10 \%$ entre as camadas do substrato. Já o resultado mais baixo, $0,18 \mathrm{MPa}$, se rompeu $80 \%$ na argamassa colante e $15 \%$ entre as camadas de gesso. Os CP's 2 e 3 apresentaram o mesmo $\mathrm{Ra}$, 0,26MPa, porém formas de ruptura distintas. Já os CP's 5 e 6, além da mesma resistência de aderência à tração, obtiveram rupturas similar.

\subsection{Resultados Para Gesso-Cola Standard}

A utilização do gesso-cola do tipo standard para assentamento da cerâmica no substrato apresentou resultados mais satisfatórios de resistência de aderência, quando comparados a ACII e ACIII. Estas tensões são expostas no Gráfico 3.

Gráfico 3: Resultados do ensaio com gesso-cola standard

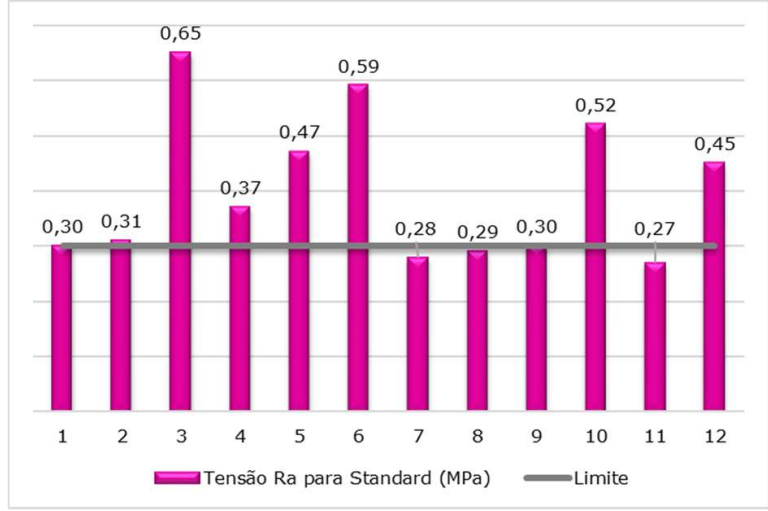

Fonte: Autores 2017

Pode-se constatar, através da análise da forma de ruptura, que os corpos de prova com Ra $\geq 0,3 \mathrm{MPa}$, CP's 1, 2, 3, 4, 5, 6, 9, 10 e 12, romperam com maior frequência entre as camadas de gesso e entre a interface substrato-gesso, apresentando também, com menor incidência, descolamentos entre a cerâmica e o gesso-cola, e nos vazios encontrados entre as camadas de gesso. Os CP's com resistência de aderência abaixo de 0,3MPa, CP's 7, 8 e 11, tiveram rupturas ocorridas entre as camadas de gesso e na interface substrato-gesso. A amostra com maior $\mathrm{Ra}, 0,65 \mathrm{MPa}$, rompeu $55 \%$ na interface substratogesso e $45 \%$ entre as camadas de gesso, enquanto que a tensão mais baixa encontrada, 0,27MPa, apresentou ruptura $100 \%$ entre as camadas de gesso. Um fator relevante é a ocorrência quase que total da ruptura entre as camadas de gesso nas três amostras com tensão menor que 0,3MPa. Esta forma de descolamento se repetiu para os CP's 8 e 11, enquanto o CP 7 rompeu $90 \%$ nesta interface e apenas $10 \%$ entre o substrato-gesso. Este fato pode ter ocorrido devido à falha de execução durante a aplicação da pasta de gesso no substrato.

\subsection{Resultados Para o Gesso-Cola Hidrofugante}

No Gráfico 4 são apresentados os resultados para o ensaio de resistência de aderência à tração com utilização de gesso-cola do tipo hidrofugante. 
Gráfico 4: Resultados do ensaio com gesso-cola hidrofugante

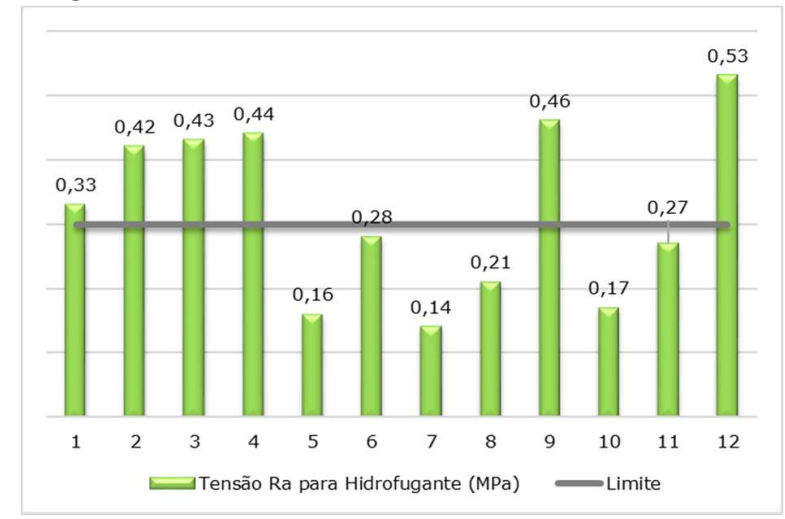

Fonte: Autores 2017

Ao final do ensaio, os corpos de prova 1, 2, 3, 4, 9 e 12 obtiveram resistência de aderência superior a $0,3 \mathrm{MPa}$, com todas as rupturas ocorrendo na interface substrato-gesso e entre as camadas de gesso. Apenas o CP 12 apresentou descolamento entre as camadas de gesso e seus vazios. Os resultados com $\mathrm{Ra} \leq$ 0,3MPa, CP's 5, 6, 7, 8, 10 e 11, apontaram todas as rupturas ocorrendo entre o substrato e o gesso, e entre as camadas de gesso. A maior resistência de aderência, 0,53MPa, rompeu $95 \%$ entre as camadas de gesso e $5 \%$ em seus vazios encontrados. Já o resultado menos satisfatório, $0,14 \mathrm{MPa}$, se rompeu $80 \%$ na interface substrato-gesso e $20 \%$ entre as camadas de gesso. A ocorrência dos descolamentos entre o substrato-gesso e entre as camadas de gesso em todas as amostras com Ra inferior a 0,3MPa, demonstram a deficiência na execução da pasta de gesso.

\subsection{Comparativo Entre os Resultados Apresentados}

Como orientado pela NBR 13749 [5], os revestimentos das áreas estudadas serão aceitos se no mínimo $2 / 3$ dos resultados de cada ensaio forem iguais ou superiores a $0,3 \mathrm{MPa}$.

Os resultados para o ensaio com a argamassa colante ACII, ilustrados no Gráfico 1 , mostraram que em um total de 12 amostras ensaiadas, apenas 6 (50\%) foram aprovadas, ou seja, o revestimento não atendeu $o$ requisito mínimo de resistência de aderência à tração, não sendo considerado de bom desempenho. Os ensaios com a argamassa colante
ACIII apresentaram resultados menos satisfatórios quando comparados a ACII. De 12 amostras ensaiadas, apenas 5 (42\%) foram aprovadas.

A utilização do gesso-cola standard na execução do revestimento cerâmico forneceu os melhores resultados, apresentando 9 corpos de prova (75\%) com resultados superiores a $0,3 \mathrm{MPa}$. O sistema construtivo onde empregou-se este tipo de material aderente foi o único aprovado dentre todos os 4 sistemas ensaiados. O gesso-cola hidrofugante, conforme observado no Gráfico 4, não obteve resultados aceitáveis, visto que apenas 6 amostras (50\%) tiveram $\mathrm{Ra} \geq 0,3 \mathrm{MPa}$.

\section{Conclusão}

Pode-se concluir que o método de ensaio utilizado não é adequado para o tipo de substrato estudado e o sistema construtivo no qual está sendo empregado. Tendo em vista que as normas técnicas sobre revestimento de gesso não abordam os requisitos mínimos de resistência de aderência, se fazem necessários estudos mais amplos quanto ao comportamento do material, como por exemplo: avaliação do tempo em aberto do gesso, resistência de aderência à tração potencial e ao longo do tempo, interferência do tipo de substrato na aderência, e aderência entre as camadas de gesso. Esse trabalho abre precedente acadêmico e técnico a respeito da utilização do gesso em áreas molhadas e molháveis, além da aplicação de cerâmica sobre substrato de gesso. Os números apresentados são considerados insatisfatórios, porém representativos no que tange a execução de cerâmica em substrato de pasta de gesso, visto que grande parte dos resultados abaixo de 0,3MPa apresentaram rupturas entre o substratogesso e entre as camadas de gesso, e não nas interfaces entre a cerâmica e a argamassa de gesso. Ainda, para este tipo de sistema construtivo, recomenda-se o desenvolvimento de pesquisas mais aprofundadas no que diz respeito a utilização do gesso-cola standard no assentamento de revestimento cerâmico, com o objetivo de comprovar o atendimento do requisito mínimo de aderência solicitado por esse sistema.

\section{Referências}

[1] CARASEK, H.; ISAIA, G.C. (Org.). Materiais de construção civil e princípios de ciência e engenharia dos materiais. São Paulo: Arte interativa, 2011. Cap. 26, p. 863-904.

http: / / dx.doi.org/10.25286/repa.v2i3.709 
[2] KAZMIERCZAK, C.S.; BREZEZINSKI, D.E.; COLLATO, D. Influências das características da base na resistência à tração e na distribuição de poros de uma argamassa. Estudos tecnológicos de engenharia, $2007 . \quad$ Disponível em: <revistas.unisinos.br/index.php/estudos_tecnolo gicos/article/view/5729/2928>. Acesso em 22 jun. 2017, 15:35:30.

[3] ASSOCIAÇÃO BRASILEIRA DE NORMAS TÉCNICAS (ABNT). NBR-13528: Revestimentos de paredes de argamassas inorgânicas - Determinação da resistência de aderência à tração. 2010.

[4] COSTA, E.B.C.; JOHN, V.M. Aderência substrato-matriz cimentícia - estado da arte. Anais IX Simpósio Brasileiro de Tecnologia das Argamassas - SBTA. 2015, Minas Gerais.

[5] ASSOCIAÇÃO BRASILEIRA DE NORMAS TÉCNICAS (ABNT). NBR-13749: Revestimentos de paredes e tetos de argamassas inorgânicas Especificação. 2013.

[6] civil. 1994.

[7] PERES, L. Gesso: Produção e utilização na construção civil. Recife: Sebrac, 2008.

[8] ASSOCIAÇÃO BRASILEIRA DE NORMAS TÉCNICAS (ABNT). NBR-13867: Revestimento interno de paredes e tetos com pasta de gesso Materiais, preparo, aplicação e acabamento. 1997.

[9] QUINÁLIA, Eliana. Gesso liso. Revista Techne, $2005 . \quad$ Disponível em: <http://techne.pini.com.br/engenhariacivil/99/artigo287379-1.aspx>. Acesso em: 23 jun. 2017, 17:54:25.

[10] ASSOCIAÇÃO BRASILEIRA DE NORMAS TÉCNICAS (ABNT). NBR-14081: Argamassa colante industrializada para assentamento de placas cerâmicas. 2012.

[11] NBR-13754: Revestimentos de paredes internas com placas cerâmicas e com utilização de argamassa colante - Procedimento. 1996.

[12] FIORITO, A.J.S.I. Manual de argamassa e revestimentos: estudos e procedimentos de execução. São Paulo: Pini, 2009.
[13] BAUER, F.L.A. Materiais de construção, 2. Rio de Janeiro: LTC, 2008. 